\title{
Erratum to: On Nested Chain Decompositions of Normalized Matching Posets of Rank 3
}

\author{
Elinor Gardner Escamilla • Andreea Cristina Nicolae • \\ Paul Russell Salerno • Shahriar Shahriari • \\ Jordan Olliver Tirrell
}

Published online: 21 August 2010

(C) Springer Science+Business Media B.V. 2010

\section{Erratum to: Order \\ DOI 10.1007/s11083-010-9164-2}

Unfortunately, we found a significant typographical error in the article.

In Theorem 1.4(d) and Theorem 5.1 of "On Nested Chain Decompositions of Normalized Matching Posets of Rank 3", the condition on rank numbers should read:

$$
r_{2}>r_{0} r_{1}-r_{0} \operatorname{gcd}\left(r_{1}, r_{2}\right)
$$

The online version of the original article can be found at http://dx.doi.org/10.1007/s11083-010-9164-2.

E. G. Escamilla · A. C. Nicolae · P. R. Salerno - S. Shahriari ( $\varangle)$

Department of Mathematics, Pomona College,

Claremont, CA 91711, USA

e-mail: sshahriari@pomona.edu

E. G. Escamilla

e-mail: elinor.escamilla@gmail.com
A. C. Nicolae
e-mail: nicolae@fas.harvard.edu
P. R. Salerno
e-mail: psalerno@ucsd.edu
J. O. Tirrell
Department of Mathematics, Lafayette College,
Easton, PA 18042, USA
e-mail: jordantirrell@gmail.com 